\title{
Contrast enhanced harmonic ultrasonography for the evaluation of acute scrotal pathology. Pictorial essay.
}

\author{
Radu Badea ${ }^{1}$, Ciprian Lucan², Mihai Suciu², Tudor Vasile', Mirela Gersak ${ }^{3}$
}

${ }^{1}$ Ultrasonography Laboratory, Imaging and Radiology Department, "Octavian Fodor" Gastroenterology and Hepatology Regional Institute, ${ }^{2}$ Clinical Institute for Urology and Renal Transplantation, ${ }^{3}$ Radiology and Imaging Department, Emergency County Hospital, "Iuliu Hațieganu” University of Medicine and Pharmacy, Cluj Napoca România

\begin{abstract}
Conventional ultrasonographic evaluation (grey scale and Doppler) represents the first line investigation in the acute pathology of the scrotum. Its diagnosis value in acute scrotal pathology is undoubted in regard with hypervascular lesions, but in the evaluation of isoechoic and hypo/avascular lesions i.v. contrast-enhanced harmonic ultrasonography (CEUS) is recommended in establishing a firm and certain diagnosis. Besides these, CEUS has an important role in the evaluation of the remaining viable testicular tissue in cases of testicular trauma, thus guiding a limited excision surgery. This paper aims to discuss the added diagnosis value of CEUS and to illustrate this through various ultrasonographic images suggestive for acute scrotum pathology.
\end{abstract}

Keywords: testicle, ultrasonography, contrast media

\section{Introduction}

In patients presenting at the emergency room with acute scrotal symptoms the first step is to distinguish between surgical and non-surgical pathology. For this, grey-scale and Doppler ultrasonography (US) represent the first line investigations [1,2].

Contrast-enhanced harmonic ultrasonography (CEUS) has been introduced in the last decade in the evaluation of scrotal pathology. The contrast media is administered intravenous $(2.4-4.8 \mathrm{ml})$, followed by a $10 \mathrm{ml}$ saline solution bolus. After approximately $20 \mathrm{sec}-$ onds, the microbubbles reach the intravascular space of the testis and may be visualized in the testicle up to 2-3 minutes after administration, then the intensity progressively decreases (wash-out phenomenon) [2-5]. CEUS presents an added diagnosis value in the acute pathology of the scrotum, being superior to non-contrast US, with

Received 06.01.2016 Accepted 25.01.2016

Med Ultrason

2016, Vol. 18, No 1, 110-115

Corresponding author: Radu Badea

3rd Medical Clinic

$19-21$ Croitorilor street

400162 Cluj Napoca

România

E mail: rbadea@umfcluj.ro a sensitivity (Se) and a specificity ( $\mathrm{Sp}$ ) up to $95 \%$ and 100 , respectively (ultrasound has an $76 \%$ Se and a $45 \mathrm{Sp}$ ) [2]. In addition to Doppler US, CEUS also has the potential of assessing intratumoral microvascularization [6-8] thus improving conventional US. CEUS is also useful as an additional examination to conventional US in acute scrotal pathology, whether it is infections/inflammatory/ vascular or traumatic.

\section{Inflammatory and infectious scrotal lesions}

Orchitis and orchiepididymitis present with acute symptoms, such as pain and swelling [9]. Most of the times the etiology is bacterial, but can also be fungal [10]. Conventional US reveals hypoechoic lesions associated with hyperemia in the affected area $[10,11]$. These inflammatory lesions show increased enhancement, correspondent with the hiperemia visualized on the Doppler examination (fig 1). On the course of its evolution, epididymitis can extend to the testis and develop complications such as abscess or infraction. Grey scale and Doppler US can identify these complications as well, but CEUS exam play an auxiliary role [10]. Therefore, in the presence of an abscess, CEUS reveals a lesion with intense, peripheral contrast uptake, while the centre of the lesion shows no uptake whatsoever (fig 2) [12]. 


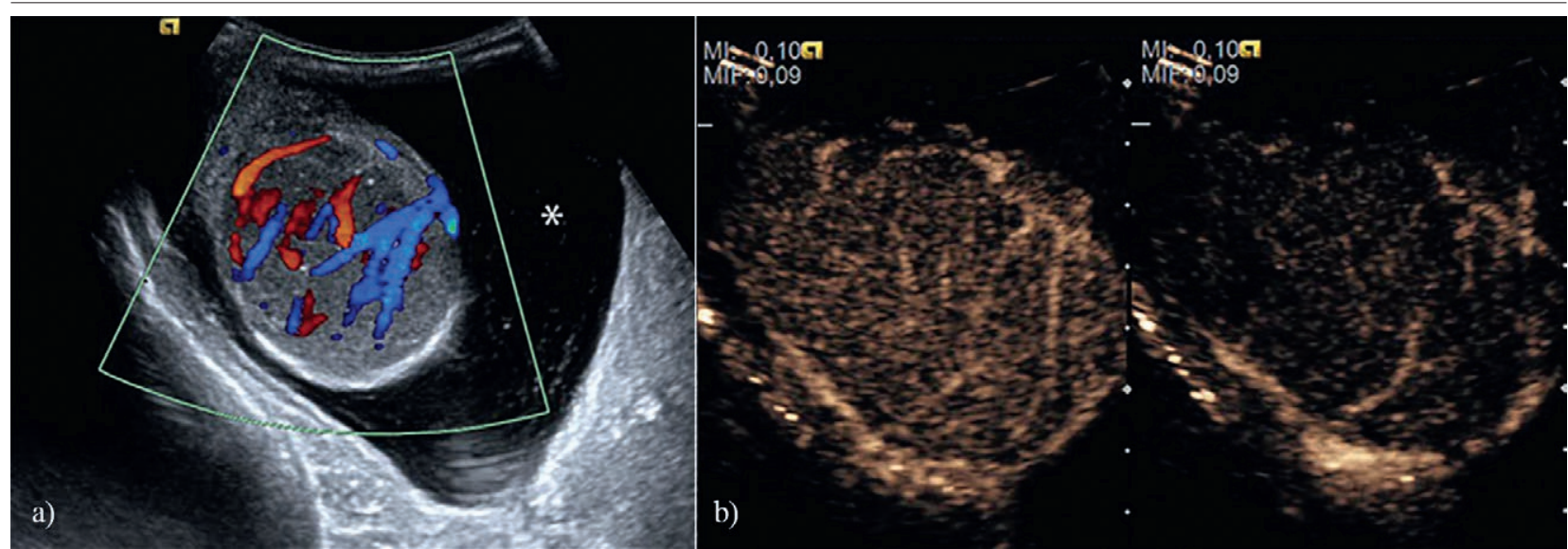

Fig 1. a) Color Doppler ultrasonography in a patient with acute orchitis. A diffuse, homogeneous hypoechogenicity associated with increased Doppler signal accompanied by a moderate hydrocele was found; Subsequently, CEUS examination was performed. There was a homogeneous enhancement of the contrast media within the testicular parenchyma in the arterial phase (b) and wash-out during the venous phase (c).

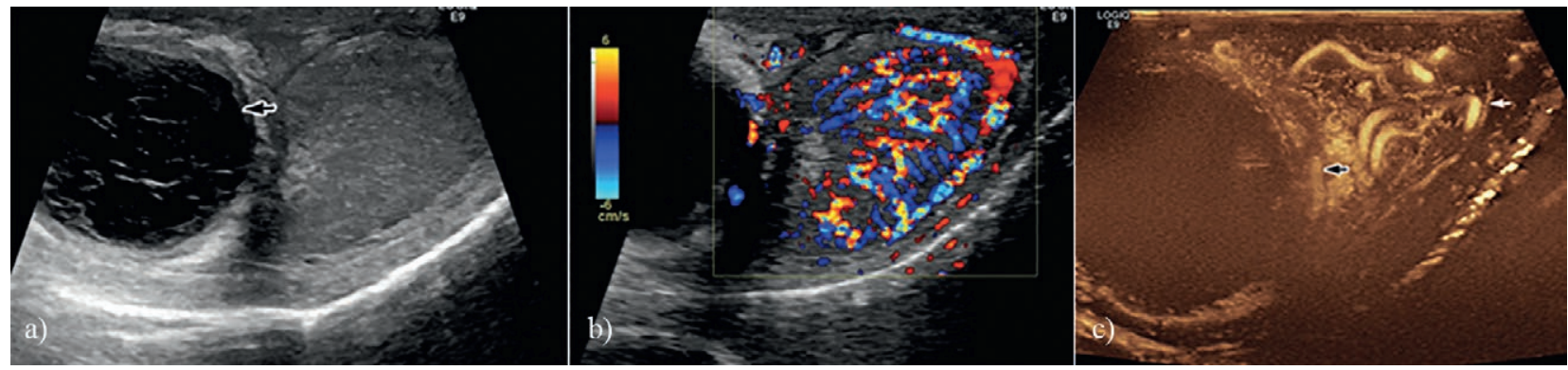

Fig 2. Orchiepididymitis associated with abscess formation within the parenchyma: a) grey-scale US- an inhomogeneous, hypoechoic lesion at the level of the epididymis with peripheral wall (abscess) was found; b) The Doppler signal was highly increased, suggestive for orchitis; c) CEUS revealed important uptake of the contrast media in the testicular parenchyma, corresponding to inflammatory changes. The epididymal lesion presented contrast-enhancement only in the periphery.

\section{Acute vascular scrotal lesions}

In acute scrotum of vascular etiology, CEUS could be of great interest especially in pediatrics, since in children, the intratesticular vascularization is physiologically reduced and Doppler evaluation is limited in testicular torsion. CEUS applications in pediatrics are still limited in the absence of an US contrast media approved for pediatric use in Europe [13].

Spermatic cord torsion represents approximately $17 \%$ of scrotal emergencies and it is an acute vascular pathology which occurs more frequently in children and young adults. It consists of a partial or complete twisting of the spermatic cord which leads to immediate circulatory alterations and impairment of the testicular function and fertility, being a surgical emergency. The main symptoms are unilateral testicular pain, accompanied by a high, transverse position of the testicle in the scrotum. The cremasteric reflex may be lost [14]. Color and Power
Doppler are elective and sufficient for the confirmation of a complete testicular torsion [12], CEUS does not bring additional information [5], but confirme the diagnosis, especially in the initial phase, allowing an early surgical intervention.

The typical alteration in acute testicular torsion is represented by the hypoechogenicity of the testicle and lack of vascular signal. In torsions which are up to $360^{\circ}$ the vascularization is often still present and the diagnosis may be missed or difficult to distinguish with the help of color Doppler alone. On the other hand, CEUS may reveal a different uptake of the contrast media within the affected testicle compared with the healthy one [5].

In the case of an old torsion, a small, atrophic testicle, with a hypoehoic centre, surrounded by a hyperechoic rim can be detected. Upon Doppler interrogation there is intratesticular vascular signal [15], but the peritesticular tissues shows increased vascularity. On the CEUS evalu- 

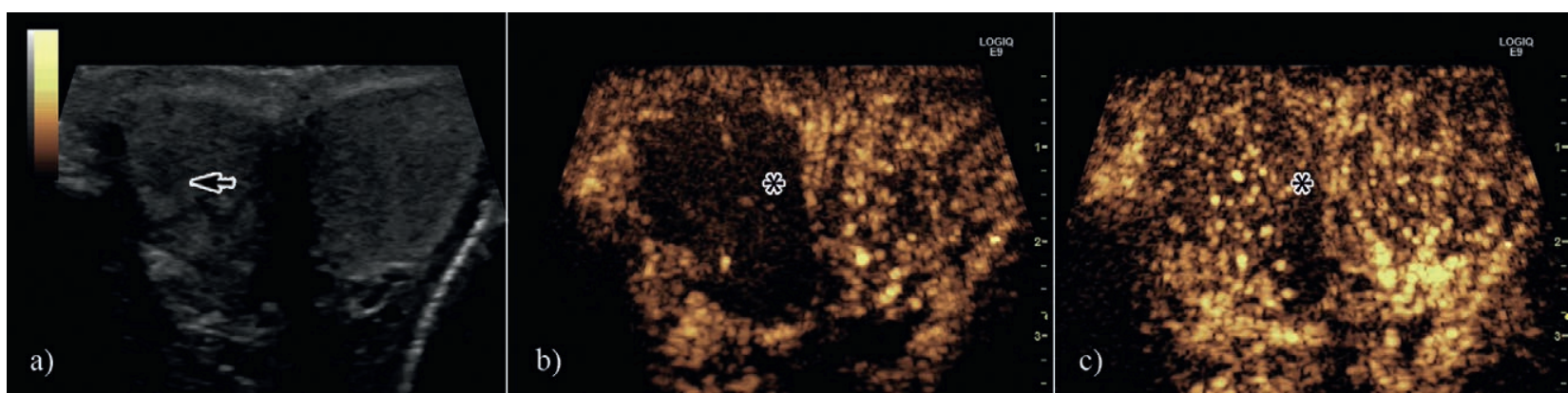

Fig 3. US in a patient with testicular torsion. Affirmatively, the twisted testicle had spontaneously untwisted, but upon the a) grey scale US, the right testicle presented an inhomogeneous structure, with a few hypoechoic, ill-defined areas (arrow). Doppler evaluation showed no signal within the testicle and for this reason CEUS was performed. During the arterial phase there was no circulatory signal (b), but in the delayed phase, after about 40 seconds, the right testicle showed a homogeneous enhancement, similar with that of the left testicle. There was a wedge-shaped small testicular area (asterisk) which was noticed only in the delayed phase, showing no CE (segmental testicular infarction) (c). This aspect is caused by a persistent torsion of the spermatic cord of up to $360^{\circ}$, a situation when such circulatory alterations may occur.
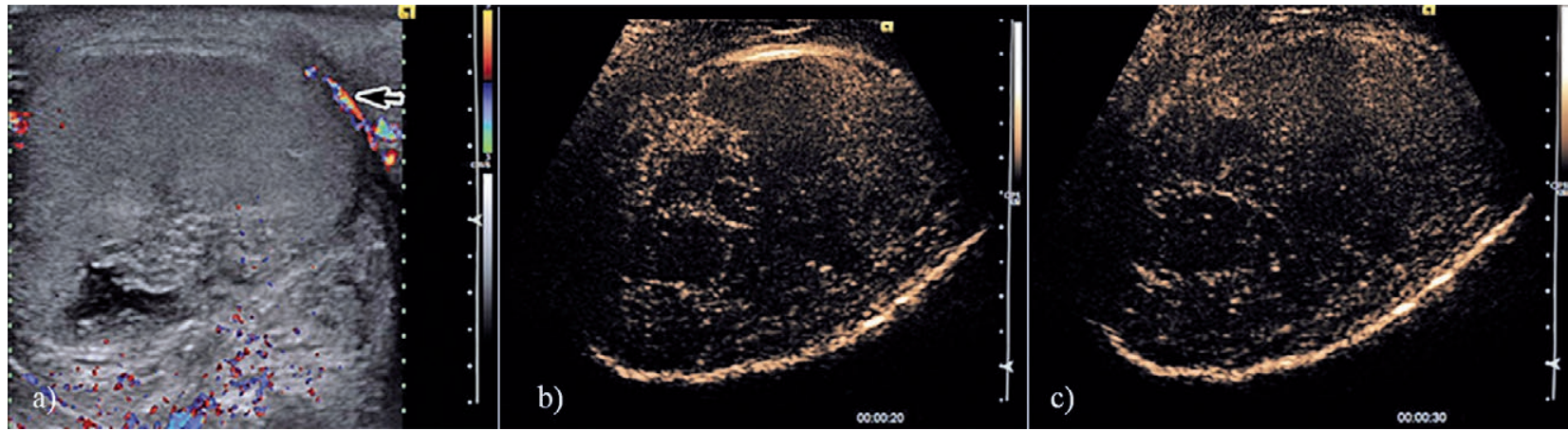

Fig 4. US in a patient with complete testicular torsion: a) The testicular parenchyma appears slightly hypoechoic, homogeneous, without vascular signal inside the parenchyma, the signal being present only at the level of the peritesticular tissues. Upon CEUS, the testicular parenchyma did not enhance during the arterial (b) or the venous phase (c).

ation there is no intratesticular enhancement [5] (fig 3, fig 4).

The torsion of the testicular epididymis and appendage is more frequently encountered in children, but also in young adults and the therapy is conservative. The testicle presents a normal US appearance. The testicular appendage has a variable aspect: most often it shows increased echogenicity and inhomogenenicity or it can be hypoechoic and present peripheral vascular signal. In evolution the appendage becomes hyperechoic, secondary to calcium depositions and it can spontaneously detach [16]. A testicular appendage $>5.6 \mathrm{~mm}$ without vascular signal is suggestive for appendage torsion [17]. The role of CEUS in the evaluation of testicular appendage torsion has not been yet described in literature. Segmentary infarction may be identified as a complication of acute orchitis/orchiepididymitis, but may also be idiopathic or encountered in testicular torsion, hypercoagulation conditions, vasculitis, or trauma. Most of the times has an hypoechoic aspect or a mixed echogenicity, it is well defined, has wedge or round shape and decreased or absent vascularity. Segmentary infarction may sometimes raise differential diagnosis issues with a hypovascular tumor $[4,18,19]$. In these cases, CEUS examination brings additional information regarding the lack of $\mathrm{CE}$ within the lesion [4]. Yet, if the patients have undergone a US examination within the first 24 hours from pain onset, the segmentary testis infarction may present a similar echogenicity as the unaffected parenchyma, but with reduced vascularity [20], a situation when a firm diagnosis may be missed. A subacute segmentary testicular infarction present peripheral uptake, most probably due to the perilesional inflammatory changes and local edema which compresses the adjacent healthy tissue [20]. That is why, in the first phase, the differential diagnosis between a subacute segmentary infarction and an abscess is rather difficult, both lesions presenting irregular margins and predominantly peripheral enhancement [21]. Nevertheless, the segmentary infarction has a lobular distribution, which in time decreases in size, it changes its aspect 


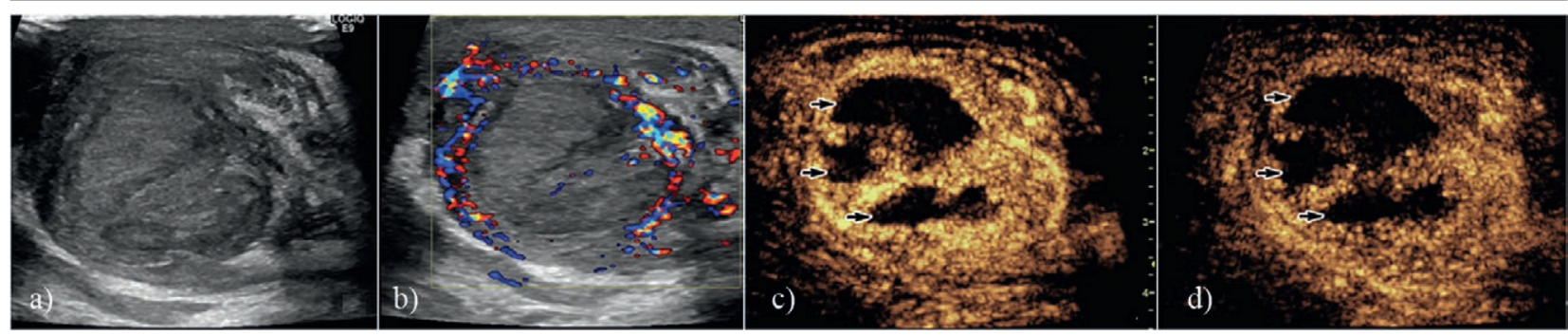

Fig 5. Testicular necrosis after testicular torsion. Grey-scale US showed an inhomogeneous parenchyma, with hypoechoic areas inside (a). During Color Doppler examination the vascular signal was absent, but there was a slightly increased vascularity of the peritesticular tissues (b). In order to evaluate the remaining viable tissue, CEUS was performed. Multiple, large areas of testicular tissue without enhancing during the arterial phase (c) or the venous phase (d) were detected. Even though there were a few vascular areas which presented uptake among the necrotic ones, the decision to remove the testicle was made.
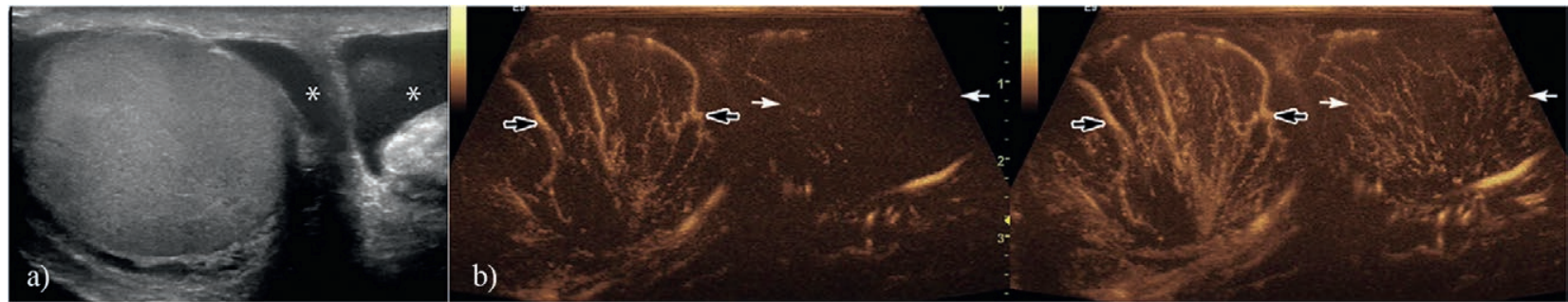

Fig 6. Patient whith right testicular concussion during a sports accident: a) Upon grey-scale examination the testicle appeared enlarged, homogeneous; b) During CEUS at the 20th second the testicle (arrows) presented an important, early uptake compared with the healthy testicle (black arrows). After 25 seconds from the contrast media administration there was a high uptake within the right testicle and moderate within the left testicle (normal). There were no areas of posttraumatic laceration detected during CEUS.

and the peripheral CE subsides after approximately 17 days. Later on, spots of intralesional vascular signal may be seen $[20,22,23]$. A few cases of complete testicular infarction have been descried in the context of previous acute epidididmitis [10]. In these situations US may show signs of epididymitis associated with a relatively normal appearance of the testicles and absence of an intratesticular vascular signal. After contrast administration a completely ischemic testicle does not enhance [10]. The differentiation of a segmentary infarction from a complete infarction is essential to the management of the patient, since in the latter a total orchiectomy is necessary [10].

\section{Posttraumatic scrotal lesions}

Traumatic pathology of the scrotum and testicle is most frequently encountered in sports and motorcycle accidents [24]. Intra or peritesticular hemorrhages may be encountered, but the scrotal wall, the epididymis, and even the urethra may also be involved [25]. The Doppler evaluation is mandatory in order to identify a possible traumatic lesion of the testicular pedicle within the spermatic cord [25].

The aspect of the hematoma or the hematocele on the US exam is variable depending on the time passed from the trauma. Immediately after the traumatic injury, the US appearance of the hematoma is echoic and in time it becomes anechoic, with or without septum inside [26]. The color Doppler examination does not reveal vascular signal inside this lesion [14].The extent of hematoceles and hematomas may be underestimated due to the similar echogenicity of the testicular parenchyma, but on the CEUS examination, they do not show any enhancement. If there is any vascular signal identified on the CEUS, this is most probably caused by an active bleeding inside the hematoma [2]. If the hematocele is not associated with testicular rupture, the treatment is conservatory [5].

In testicular fracture the contour of the testicle and the tunica albuginea are intact, but there is at least one trajectory across the testicular parenchyma that may be associated with a hematoma. The testicular parenchyma is disorganized [26]. A testicular fracture may pass unnoticed if there is masive testicular edema or it may appear as an hypoechoic line passing through the testicle, with or without an associated intratesticular hematoma. Color Doppler evaluation does not reveal any signal at this level [14,21]. CEUS detects best the viable testicular tissue and its delimitation as well as the fracture line $[2,27]$ and the aspect is correlated with the severity of the trauma: in testicular contussion there is a homogeneous, 


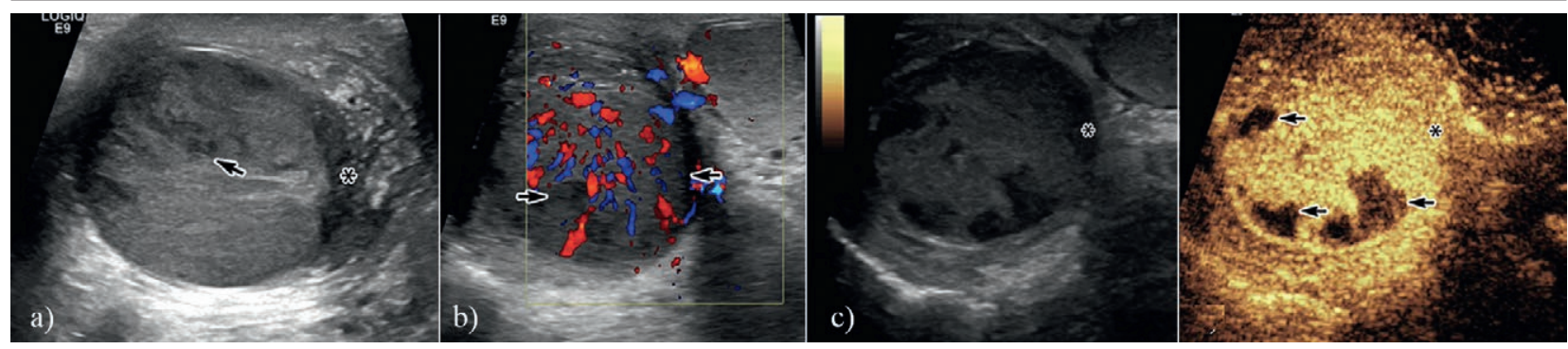

Fig 7. Patient with a car accident: a) Grey-scale examination revealed an inhomogeneous parenchyma, with hypoechoic areas (arrow). Immediately under the capsule, a hypoechoic, ill-circumscribed area was identified (asterisk), which made it impossible to clearly determine whether there was capsular lesion or not; b) Color Doppler revealed a slightly hypervascular testicular parenchyma, with hypovascular areas (arrows); c) CEUS identified during the arterial phase areas of viable tissue with contrast-enhancement, as well as areas of non-viable tissue whithout enhancement (arrows). The subcapsular lesion detected with grey-scale US presented enhancement, thus corresponding to a viable tissue area (asterisk). Also, with the help of CEUS the testicular capsule was evaluated and it was clear that it had not been interrupted.

almost normal uptake; while in a severe trauma, associated with fracture, the CE is inhomogeneous, scattered, and weak (fig 7). When testicular trauma is associated with torsion or the testicle is entirely disorganized no $\mathrm{CE}$ is found [12,27].

In testicular rupture there is a solution of continuity of the tunica albuginea with herniation of testicular parenchyma [14]. Conventional US is capable to identify testicular rupture with a Se of up to $100 \%$ and a Sp of 65\% [28]. Additionally, US may show hyper of hypoechoic focii which correspond to hematomas, infarctions, or hematoceles [26], but cannot differentiate between herniated parenchyma and a hematoma with similar echogenicity [24]. CEUS examination can identify intratesticular fluid collections which develop early in a trauma, as well as their extent and the solution of continuity at the level of tunica albuginea [24]. The CEUS exam has an im portant role in traumatic scrotal pathology in situations when conventional US cannot clearly establish if surgery is needed or not [5] (for example in the case of a hematocele without a clear testicular fracture line on the conventional US) or it cannot define the complete extension of the lesions (such as in the situation of a hematoma with an echogenicity similar with that of the testicular parenchyma or for the evaluation of the testicular tissue viability).

Conclusion. The conventional US appearance is most frequently suggestive in the evaluation of the acute scrotum. The added role of CEUS is significant especially in testicular torsion and in the complications of acute orchitis/epididymitis, when it can bring information which are subtle or non-existent on conventional ultrasound. Also, CEUS presents a significant additional value in the assessment of testicular trauma, being capable to identify the extent of the lesions, possible hematomas and non viable testicular tissue.

\section{Conflict of interest: none}

\section{References}

1. Dogra VS, Gottlieb RH, Oka M, Rubens DJ. Sonography of the scrotum. Radiology 2003; 227: 18-36.

2. Valentino M, Bertolotto M, Derchi L, et al. Role of contrast enhanced ultrasound in acute scrotal diseases. Eur Radiol 2011; 21: 1831-1840.

3. De Zordo T, Stronegger D, Pallwein-Prettner L, et al. Multiparametric ultrasonography of the testicles. Nat Rev Urol 2013; 10: 135-148.

4. Valentino M, Bertolotto M, Martino P, Barozzi L, Pavlica $\mathrm{P}$. Incidentally detection of non-palpable testicular nodules at scrotal ultrasound: What is new? Arch Ital Urol Androl 2014; 86: 378-382.

5. Moschouris H, Stamatiou K, Lampropoulou E, Kalikis $\mathrm{D}$, Matsaidonis D. Imaging of the acute scrotum: is there a place for contrast-enhanced ultrasonography? Int Braz J Urol 2009; 35: 692-705.

6. Patel K, Sellars ME, Clarke JL, Sidhu PS. Features of testicular epidermoid cysts on contrast-enhanced sonography and real-time tissue elastography. J Ultrasound Med 2012; 31: 115-122.

7. Sidhu PS, Allan PL, Cattin F, et al. Diagnostic efficacy of SonoVue, a second generation contrast agent, in the assessment of extracranial carotid or peripheral arteries using colour and spectral Doppler ultrasound: a multicentre study. $\mathrm{Br}$ J Radiol 2006; 79: 44-51.

8. Horstman WG, Melson GL, Middleton WD, Andriole GL. Testicular tumors: findings with color Doppler US. Radiology 1992; 185: 733-737.

9. Nicholson A, Rait G, Murray-Thomas T, Hughes G, Mercer $\mathrm{CH}$, Cassell J. Management of epididymo-orchitis in primary care: results from a large UK primary care database. Br J Gen Pract 2010; 60: e407-e422.

10. Yusuf G, Sellars ME, Kooiman GG, Diaz-Cano S, Sidhu PS. Global testicular infarction in the presence of epididymitis clinical features, appearances on grayscale, color doppler, 
and contrast-enhanced sonography, and histologic correlation. J Ultrasound Med 2013; 32: 175-180.

11. Cook JL, Dewbury K. The changes seen on high-resolution ultrasound in orchitis. Clin Radiol 2000; 55: 13-18.

12. Cokkinos DD, Antypa E, Kalogeropoulos I, et al. Contrastenhanced ultrasound performed under urgent conditions. Indications, review of the technique, clinical examples and limitations. Insights Imaging 2013; 4: 185-198.

13. Piscaglia F, Nolsøe C, Dietrich C, et al. The EFSUMB Guidelines and Recommendations on the Clinical Practice of Contrast Enhanced Ultrasound (CEUS): update 2011 on non-hepatic applications. Ultraschall Med 2012; 33: 33-59.

14. Yusuf GT, Sidhu PS. A review of ultrasound imaging in scrotal emergencies. J Ultrasound 2013; 16: 171-178.

15. Traubici J, Daneman A, Navarro O, Mohanta A, Garcia C. Original report. Testicular torsion in neonates and infants: sonographic features in 30 patients. AJR Am J Roentgenol 2003; 180: 1143-1145.

16. Lerner RM, Mevorach RA, Hulbert WC, Rabinowitz R. Color Doppler US in the evaluation of acute scrotal disease. Radiology 1990; 176: 355-358.

17. Baldisserotto M, de Souza JC, Pertence AP, Dora MD. Color Doppler sonography of normal and torsed testicular appendages in children. AJR Am J Roentgenol 2005; 184: 1287-1292.

18. Fernández-Pérez GC, Tardáguila FM, Velasco $\mathrm{M}$, et al. Radiologic findings of segmental testicular infarction. AJR Am J Roentgenol 2005; 184: 1587-1593.

19. Bilagi P, Sriprasad S, Clarke JL, Sellars ME, Muir GH, Sidhu PS. Clinical and ultrasound features of segmental testicular infarction: six-year experience from a single centre. Eur Radiol 2007; 17: 2810-2818.
20. Bertolotto M, Derchi LE, Sidhu PS, et al. Acute segmental testicular infarction at contrast-enhanced ultrasound: early features and changes during follow-up. AJR Am J Roentgenol 2011; 196: 834-841.

21. Cantisani V, Bertolotto M, Weskott HP, et al. Growing indications for CEUS: The kidney, testis, lymph nodes, thyroid, prostate, and small bowel. Eur J Radiol 2015; 84: 1675-1684.

22. Patel KV, Huang DY, Sidhu PS. Metachronous bilateral segmental testicular infarction: multi-parametric ultrasound imaging with grey-scale ultrasound, Doppler ultrasound, contrast-enhanced ultrasound (CEUS) and real-time tissue elastography (RTE). J Ultrasound 2014; 17: 233-238.

23. Huang DY, Sidhu PS. Focal testicular lesions: colour Doppler ultrasound, contrast-enhanced ultrasound and tissue elastography as adjuvants to the diagnosis. $\mathrm{Br} \mathrm{J}$ Radiol 2012; 85(SpecNo 1): S41-S53.

24. Lobianco R, Regine R, De Siero M, Catalano O, Caiazzo C, Ragozzino A. Contrast-enhanced sonography in blunt scrotal trauma. J Ultrasound 2011; 14: 188-195.

25. Terlecki RP. Testicular Trauma. Cited 2016 Jan 15. Available from: http://iranianpda.net/medscape/A441362-business.html

26. Deurdulian C, Mittelstaedt CA, Chong WK, Fielding JR US of acute scrotal trauma: optimal technique, imaging findings, and management. Radiographics 2007; 27: 357-369.

27. Hedayati V, Sellars ME, Sharma DM, Sidhu PS. Contrastenhanced ultrasound in testicular trauma: role in directing exploration, debridement and organ salvage. Br J Radiol 2012; 85: e65-e68.

28. Guichard G, El Ammari J, Del Coro C, et al. Accuracy of ultrasonography in diagnosis of testicular rupture after blunt scrotal trauma. Urology 2008; 71: 52-56. 